\title{
Topical anesthetic efficacy on palatal mucosa pretreated with microneedles
}

\section{Augusto GGX ${ }^{\star}$, Santos SC, Moreira NCF, Abdalla HB, Volpato MC, Groppo FC, Gill HS, Leite MFMB}

\section{Abstract}

This research evaluated whether topical anesthetic efficacy increases on palatal mucosa pretreated with microneedles.

\author{
Key words: \\ Microneedles, Topical Anesthetic, Oral mucosa.
}

\section{Introduction}

This research evaluated whether topical anesthetic efficacy increases on palatal mucosa pretreated with microneedles.

\section{Results and Discussion}

In this crossover, randomized, double-blind study, 20 male volunteers were submitted to topical application of microneedles or flat patches on palatal mucosa, bilaterally in the canine region followed by topical anesthesia procedure with EMLA® (Eutectic mixture of lidocaine and prilocaine) during 2 or 5 minutes. Immediately after, an infiltrative anesthesia was performed by using a 30-gauge short needle and $0.3 \mathrm{~mL}$ of lidocaine $2 \%$ with epinephrine $1: 100,000$. Pain sensation during needle insertion and local anesthetic injection was evaluated by using 2 different visual analogical scale (VAS). VAS (in $\mathrm{mm}$ ) results The use of microneedle as a pretreatment of palatal mucosa did not increase topical anesthetic efficacy of EMLA in reducing pain during needle insertion or local anesthetic injection after 2 min of topical application. However the efficacy of EMLA after 5 minutes of application resulted in reduction of pain during needle insertion, but not to local anesthetic injection ( $p>0.05)$.

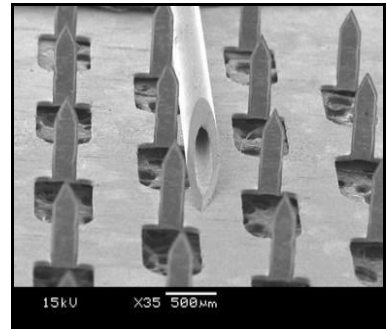

Image 1. MEV - Microneedles and hypodermic needle.

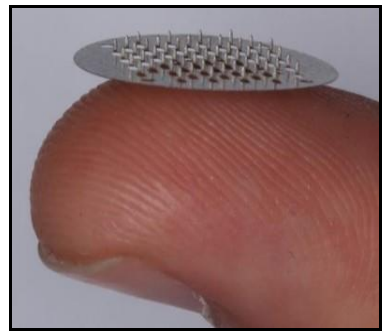

Image 2. Patch of microneddles.

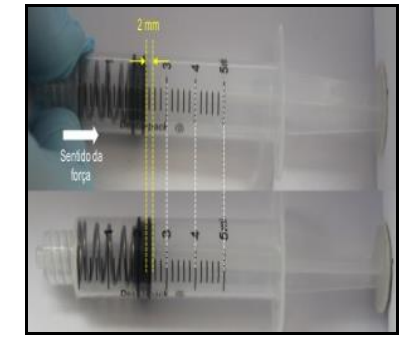

Image 3. Application device.

\section{Conclusions}

In conclusion, microneedle treatment of palatal mucosa was able to increase topical anesthetic efficacy of EMLA®

Fapesp $N^{\circ}$ 2017/19032-0

\section{Acknowledgement}

1. AL-MELH, M. A. \& ANDERSSON, L. (2007). Comparison of topical anesthetics (EMLA/Oraqix vs. benzocaine) on pain experienced during palatal needle injection. - Oral Surg Oral Med Oral Pathol Oral Radiol Endod 103, e16-20

2. - - (2008). Reducing pain from palatal needle stick by topical anesthetics a comparative study between two lidocaine/prilocaine substances. — J Clin Dent 19, 43-7.

3. ARMFIELD, J. M. \& MILGROM, P. (2011). A clinician guide to patients afraid of dental injections and numbness. - SAAD Dig 27, 33-9.

4. Bal, S. M., Caussin, J., Pavel, S. \& Bouwstra, J. A. (2008). In vivo assessment of safety of microneedle arrays in human skin. - Eur J Pharm Sci 35, 193-202.

5. BARIYA, S. H., GOHEl, M. C., MeHTA, T. A. \& Sharma, O. P. (2012) Microneedles: an emerging transdermal drug delivery system. — J Pharm Pharmacol 64, 11-29.

6. CORMIER, M., JOHNSON, B., AMERI, M., NYAM, K., LiBIRAN, L. ZHANG, D. D. \& DADDONA, P. (2004). Transdermal delivery of desmopressin using a coated microneedle array patch system. - J Control Release 97, 503-11.

7. Franz-Montan, M., De Paula, E., Groppo, F. C., Silva, A. L. RANALI, J. \& VOLPATO, M. C. (2010a). Liposome-encapsulated ropivacaine for intraoral topical anesthesia. - Oral Surg Oral Med Oral Pathol Oral Radiol Endod 110, 800-4.

8. - (2012a). Liposomal delivery system for topical anaesthesia of the palatal mucosa. - Br J Oral Maxillofac Surg 50, 60-4.

9. Franz-Montan, M., De Paula, E., Groppo, F. C., Silva, A. L. R. RANALI, J. \& VOLPATO, M. C. (2012b). Liposomal delivery system for topical anaesthesia of the palatal mucosa. - British Journal of Oral \& Maxillofacial Surgery 50, 60-64. 